\title{
A Comparison of US and Turkish Perspectives of Generations
}

\author{
Michael J Urick* and Alperen Arslantas \\ Assistant Professor, Saint Vincent College, USA
}

*Corresponding author: Michael J. Urick, Alex G. McKenna School of Business, Economics and Government, St. Vincent College, Aurelius Hall 215, 300 Fraser Purchase Rd, Latrobe, USA

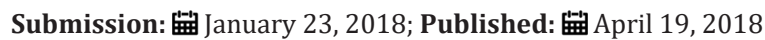

\begin{abstract}
This paper explores cross-culture generational phenomena, specifically within the context of the workplace, using Turkey and the US as comparisons. In a short discussion of popular press and academic publications, we compare perceptions of generational groupings in both cultures. In doing so, we find both surprising similarities and differences. We advocate that more research in the area of international generational phenomena occur in order to support or refute our preliminary statements.
\end{abstract}

Keywords: Generations; USA; Turkey; International comparison

\section{Introduction}

The purpose of this paper is to explore the concept of "generation" across cultures. In doing so, we will consider whether the generational concept is similar across the US and Turkish contexts. We also look at the potential importance of generational issues in Turkey. Many different understandings of the term "generation" exist [1]. One common understanding within the US is that generations are cohorts or groups that consist of people who belong to the same age group and, accordingly, consist of people who share similar experiences in the years that fundamentally shape their lives [2]. However, it is questionable whether or not such generational categories are relevant in various countries around the globe since generational cohorts could also be influenced by the historical development of a country. The macro-level social, political and economic events of the historical period effect the individuals during formative ages of development and hence potentially their values and belief systems. Similarly, such macro level considerations could influence expectations and behaviors of the generation that they are in. The influence of macro considerations has implications for intergenerational interactions. In their study of workplace age phenomena, Urick and colleagues [3] found that such societal-level forces are highly influential to the way that generational categories and their members are perceived

\section{Comparing US and Turkish Generational Perspectives}

From a review of both academic and popular press oriented literature, we note both similarities and differences in the generational categories between Turkey and the US. For example many of the age ranges are similar between US and Turkish cultures.
Although the concept of "generation" has wide-spread acceptance across cultures, there are differences between cross-cultural generational groupings [4]. Though sharing some similar labels, overlapping birth years and some characteristics, generations in Turkey are also influenced by localized events in the Turkish context.

Individuals born before 1945 are referred to as the Silent Generation or Traditionals in the US [5]. Given the events that the Silent Generation of Turkey experienced in the years 1900-1945, they are be labeled as the Great Change Generation or First War Generation. In Turkey, the existence of this generational group corresponds to the newly established republic [6]. Concerning influences on this group, the negative effects of the war years caused insufficient levels of income and education over Turkey's population during this generation's formative years. Although Turkey experienced some improvement in the areas of population, education and health by the end of 1945, individuals who lived during this period still had quite low standards of life compared to today's standards of living [7].

Individuals born between the years 1946-1964 are a part of the Boom Generation (Baby Boomers in the US), a generation that experienced growth, prosperity and a sense of longing for goods and services. The Baby Boomer generation stands out as a group that exerted a lot of influence in the 1960s both within the US and Turkey as this group is perceived as breaking down divisions (especially in Turkey) which were necessary for continued improvements related to quality of life. 
Generation $\mathrm{X}$ is a transitional generation and is labeled the "Transition Period Children" or "Lost Generation" in Turkey, their proportion of the total population is $17.4 \%$ (13 million people) according to data from 2012 [8]. As a whole, they are perceived to be sensitive to social problems, loyal, idealistic, skeptical and challenging. Due to the concurrent technological revolution, they began to use technology on a regular basis. It is suggested that they are the first generation interested in "brands," and many generational members perhaps even started to define their identity according to particular brands. This generation also shows respect to authority, is highly motivated at work, loyal to their employers and has increased levels of satisfaction. Concerns about their future caused this generation to focus on working more, making a career and earning more money $[9,10]$. Generation $X$ also witnessed changes to the traditional Turkish family model with the increased entrance of women into business life and a decrease in the number of children in each family. Additionally, demographic researchers draw attention to Generation X as being more fortunate compared to the previous crowded Boomers Generation and are considered to be less competitive [11]. Generation X in Turkey is defined as a generation which is well-educated, open-minded and acts more individually-oriented compared to the previous generations [12].

Generation Y (Millennials, Echo Boom or Next Generation in the US) is often called the "After 80 Generation" in Turkey and their proportion of the total population is $25.1 \%$ which is 18 million people according to data from 2012. Generation Y is thought to be comprised of technology adopting, individual-oriented and relaxed children of the globalized world which experienced the innovations of technological revolutions [8]. The most distinctive features separating Generation Y from Generation X are their voluntary relationships with fast-growing technology and consumption patterns. For example, Generation Y members acquire multiple online identities thanks to their tendencies toward internet usage. The internet's virtual world has seemingly competed with the real world to Generation Y as it offers members ways to establish themselves and their relationships through virtual worlds' and symbols [9]. Being born in this era of huge technological innovations provides Generation Y members familiarity to the technological tools. Also, the freedom of thought which came from being able to reach information more easily increases their expectations for their educational life and overall world view. Generation Y experienced being raised by divorced parents, working mothers and increased ethnic diversity in Turkey. Because the internet provides international communication abilities, Generation Y is distinct as being the first global consumer group [13].

\section{Additional Turkish Considerations}

Despite some obvious similarities, there are a number of differences between US and Turkish perspectives on generations. For example, the Millennium Generation (Millenials) in Turkey is usually discussed as a generational cohort separate from Generation $\mathrm{Y}$ (which is different from discussion in the US where these two terms are usually thought to be synonymous) and is often called the
"Digital Cohort" in Turkey. The proportion of the total population of this group is $17.1 \%$ (12 million people) according to gathered data in 2012. Like Generation Y, the Millennials are a generation which is aware of new developments in technology. However, while they are also considered knowledgeable in a wide variety of topics and talented, at the same time they are perceived to be lonely and withdrawn.

In Turkey, understanding generational phenomena has become increasingly important. For example, challenging intergenerational interactions have become one of the most fundamental problems of human resource managers [14] and future research must be done in order to reduce conflicts and to understand more about the younger generations and their expectations. A report in "Capital Magazine" in Turkey of 50 businesses showed that the working age has been trending downward and suggests that young people can quickly adapt to innovation and change, are faster at learning how to use technology and are comfortable with developing new ideas. If these perceptions are accurate, their adaptable fast-learning attitude could improve organizational efficiency by providing positive outcomes for their companies and improving their performance. However, this generation is also perceived to require high amounts of feedback and is de-motivated by strict control [15]. Of note is that, though often assumed that generations are localized, despite some differences noted above, the generational groupings between Turkey and the U.S. share some striking similarities [16]. For instance, as generations progressed, each ushered in new advances in quality of life in both cultures. Similarly, the prevalence of and access to technology in both contexts were heavily influential in terms of information prevalence and communication challenges and abilities. Future research might consider how similar perspectives of generation groups emerge at roughly the same time between contexts despite geographic and cultural distances [17].

Examining generational issues in Turkey is important because, as of the 2011 workforce, $32 \%$ of non-managers and $20 \%$ of managers were members of Generation Y. In Turkey, due to these numbers, a large number of companies are working to shape their business processes to accommodate younger generations. However, as as Urick and colleagues [3] note, differences in generations may be based more on perception than true behavioral or values-based discrepancies in a US context. More research, therefore, is needed in the context of other cultures regarding generational phenomena [17]. This paper is a preliminary examination of generations in the Turkish culture and comparison of them with the US perspective. Given the importance of generational issues in Turkey and around the globe, more work is needed specifically with regard to whether or not generational groupings (and the generation concept more generally) are similar around the world. Given that international studies related to generational phenomena in the workplace are lacking, we recommend that future research analyze empirical data related to similarities and differences of generations across cultures. Such research will be informative to the statements in this pilot examination of popular and academic literature that suggest both surprising differences and similarities between cultures. 


\section{References}

1. Joshi A, Dencker JC, Franz G (2011) Generations in organizations. Research in Organizational Behavior 31: 177-205.

2. Kupperschmidt BR (2000) Multigeneration employees: strategies for effective management. The Health Care Manager 19(1): 65-76.

3. Urick MJ, Hollensbe EC, Masterson SS, Lyons ST (2016) Understanding and Managing Intergenerational Conflict: An Examination of Influences and Strategies. Work, Aging and Retirement.

4. Egri CP, Ralston DA (2004) Generation cohorts and personal values: A comparison of China and the United States. Organization Science 15(2): 210-220.

5. Kyles D (2005) Managing your multigenerational workforce. Strategic Finance 87(6): 52.

6. Senbir H (2004) Z Son İnsan Mr? O Kitaplar.

7. Erden Ayhün S (2013) Differences between Generations and organizational rebounds. MuğlaSitki Koçman University, Faculty of Economics and Administrative Sciences, Economics and Management Research Magazine 2(1):

8. (2012) Statistical Indicators Statistical Indicators.

9. Altuntuğ N (2012) The birds are going to be the victim and the future consumer profile. The organizational report 4(1):
10. Carrigan E (1994) Where to reach today's young-adult generation. Advertising Age 19: 23-35.

11. Okan EY, Yalman N (2013) Türkiye'de Tartıșmalı Reklamlar: Kuşaklar Arası Karşılaştırma. Hacettepe Üniversitesiliktisadive İdari Bilimler Fakültesi Dergisi 31(2):

12. Keleş HN (2011) Load scene is a study of the motivation profiles of the handicrafts in the determined mental field. Organization and Management Science Magazine 3(2):

13. Knight DK, Young Kim E (2007) Japanese consumers' need for uniqueness: Effects on brand perceptions and purchase intention. Journal of Fashion Marketing and Management: An International Journal 11(2): 270-280.

14. Yüksekbilgili Z (2015) Türkiye'de Y Kuşağinin Yaş Araliği. Elektronik Sosyal Bilimler Dergisi 14(53): 259-267.

15. Egri CP, Ralston DA (2004) Generation cohorts and personal values: A comparison of China and the United States. Organization Science 15(2): 210-220.

16. Mannheim K (1952) The problem of generations. Psychoanalytic Review 57(3): 378-404

17. Pilcher J (1994) Mannheim's sociology of generations: an undervalued legacy. British Journal of Sociology pp. 481-495.

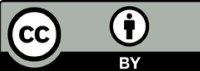

Creative Commons Attribution 4.0 International License

For possible submissions Click Here

\section{Submit Article}

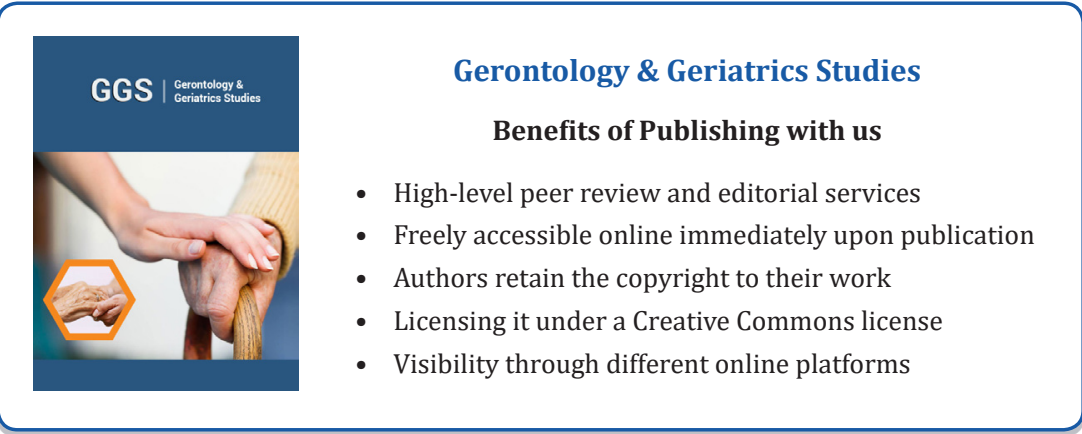

